\title{
REFLEXIONES SOBRE LAS IMÁGENES FEMENINAS. ALICIA D'AMICO E ILSE FUSKOVÁ EN LUGAR DE MUJER
}

\author{
Reflections on female images. Alicia D'Amico and \\ Ilse Fusková in Woman's Place
}

\author{
María Laura Rosa*
}

\begin{abstract}
RESUMEN
Unos meses antes a la recuperación democrática, Buenos Aires asistió a la conformación de Lugar de Mujer, un espacio de reunión para todas las mujeres. Allí comenzaron un importante trabajo de recuperación de los lazos sociales perdidos por la dictadura militar. En este contexto las mujeres buscaron recuperar una voz propia. Alicia D'Amico realizó varios wokshops en este espacio, junto con la psicóloga Graciela Sikos. En ellos investigó cómo a través de la fotografía las mujeres podían encontrarse con ellas mismas y alcanzar una imagen propia. Por entonces Ilse Fusková estaba en las mismas búsquedas que D'Amico. En su serie El zapallo, la fotógrafa analiza la mirada femenina hacia el cuerpo desnudo de una mujer. Este artículo busca pensar la importancia de la reflexión sobre el propio cuerpo a través de la imagen de dos fotógrafas feministas, Alicia D'Amico e Ilse Fusková, quienes en un momento de recuperación de los vínculos afectivos y políticos, mostraron cómo las mujeres propusieron otras miradas hacia sus propios cuerpos y deseos.
\end{abstract}

Palabras claves: Arte feminista- Fotógrafas argentinas- Arte Contemporáneo

* Professora do Consejo Nacional de Investigaciones Científicas y Técnicas de la Universidad de Buenos Aires (UBA-CONICET). E-mail: marialaurarosa@hotmail.com 


\begin{abstract}
A few months before the democratic recovery, Buenos Aires attended the creation of Lugar de Mujer, a meeting place for all women. They began there an important work of recovering the social ties lost by the military dictatorship. In this context, the women sought to recover their own voice. Alicia D'Amico made several wokshops in this place with the psychologist Graciela Sikos. D'Amico began her reserch about how women could meet themselves and achieve their own image through photography. By then Ilse Fusková began the same searches as D'Amico. In her series El zapallo, the photographer analyzes the female gaze towards the naked body of a woman. This article seeks to think about the importance of reflection on one's own body through the image of two feminist photographers, Alicia D'Amico and Ilse Fusková, who in a moment of recovery of affective and political bonds, showed how women proposed other looks towards their own bodies and desires.
\end{abstract}

Keywords: Feminist art - Argentinian Photographers Contemporary Art

\title{
Reflexiones sobre las imágenes femeninas. Alicia D’Amico e Ilse Fusková en Lugar de Mujer
}

\section{La recuperación democrática en el origen de Lugar de Mujer}

Tras el golpe de estado del 24 de marzo de 1976, se produjo en el campo cultural argentino un corte abrupto de cara a las experimentaciones que se venían gestando desde los años 60 . La profunda desarticulación de este ámbito debido a la desaparición, el exilio o el insilio ${ }^{1}$ de muchas/os de sus protagonistas, no fue saldada sino hasta varios años después de iniciada la democracia.

\footnotetext{
${ }^{1}$ Hablo de insilio para referir al silencio o exilio interno dentro del propio país.
} 
El gobierno de facto redujo y luego paralizó la acción de varios grupos que luchaban desde finales de los años 60 por la liberación sexual, la autonomía de los cuerpos y el aborto. Entre ellos se encontraban la Unión Feminista Argentina (UFA), el Movimiento de Liberación Femenina o Feminista $(M L F)^{2}$ y el Frente de Liberación Homosexual (FLH). En un contexto en el que se abogaba por los cambios sociales, estas agrupaciones originadas durante los últimos años de la década del 60 y los primeros años de la del 70 , planteaban la imposibilidad de la revolución social sin antes llevar a cabo una sexual, es decir, el final del patriarcado debía producirse antes que el final del capitalismo. Junto a los encuentros de estudio y discusiones teóricas se sumaron acciones directas: la difusión de volantes en la calle y el boicot a los eventos sexistas o en donde se sostenía la patologización de la homosexualidad. También se realizaron fanzines y se desarrollaron publicaciones como Somos, la revista del FLH que salió entre 1973 y 1976 o Persona, publicación del MLF, que se editó entre 1974 y 1982.

Con el regreso democrático, el 10 de diciembre de 1983, el país asistió lentamente a la reconstrucción de los vínculos afectivos que se habían deteriorado profundamente durante el régimen. El retorno de exiliados y exiliadas tuvo un impacto inmediato en el campo cultural. Asimismo, las agrupaciones feministas, que habían comenzado a rearticularse durante el último año de la dictadura, retomaron las luchas mencionadas de los 70 .

En ese sentido, hacia el final del gobierno de facto, DIMA (Derechos Iguales para la Mujer Argentina), institución fundada por Sara Rioja en 1976, organizó tres importantes actividades que evidenciaron el trabajo subterráneo realizado por el feminismo local, destacando las urgencias de las mujeres argentinas ante temas como trabajo doméstico, derechos laborales, salud, familia y creación, entre otras cuestiones. Una de ellas fue el Primer Congreso Argentino La Mujer en el Mundo de Hoy - 25 y 26 de octubre de 1982 -. Otra de las actividades fueron las Jornadas de la Creatividad Femenina - 1, 2 y 3 de abril de 1983 -, cuyo lema fue 'En toda mujer hay una creadora y

\footnotetext{
${ }^{2}$ Su fundadora, María Elena Oddone lo nombró Movimiento de Liberación Femenina. A finales de los años 70 reemplaza este término por el de Feminista.
} 
en toda creadora hay una mujer'. Finalmente, en el mes de mayo de ese mismo año, se realizó el Segundo Congreso La Mujer en el Mundo Hoy. Fue por entonces que, gracias a la idea de la feminista Marta Miguelez durante las Jornadas de la Creatividad Femenina, el 13 de agosto de 1983 abrió sus puertas en la ciudad de Buenos Aires Lugar de Mujer ${ }^{3}$. Las mujeres señalaron los objetivos de su fundación el mismo día de su inauguración:

Porque vamos a reunirnos para hablar de nosotras, desarrollando el respeto y la solidaridad, revisando los modelos convencionales de vinculación social. Porque somos conscientes de la necesidad de un lugar permanente de encuentro. Porque queremos revisar los prejuicios y tabúes que nos desprestigian y nos desvalorizan. Porque queremos rever los modelos dentro de los cuales fuimos educadas. Porque pensamos que el autoritarismo, la rivalidad y la competitividad atentan contra un modo de vida creativo y auténtico. Porque sí. ¿Para qué? Para reflexionar sobre nuestra inserción en la sociedad; discutir acerca de nuestro cuerpo, sexualidad, afectos creatividad, vínculos, identidad. ${ }^{4}$

Lugar de Mujer fue un espacio pluralista que recibió a mujeres de todas las tendencias políticas, feministas y no feministas. Su creación vino a saldar el vacío existente en relación con un espacio convocante para aquellas que no necesariamente eran académicas ni pertenecían a centros de estudios de la mujer pero que sentían la necesidad de reflexionar sobre la situación del colectivo femenino. Allí se realizaron actividades que tenían como objetivo fundamental la toma de conciencia de que las problemáticas femeninas formaban parte de la estructura patriarcal. Ese sentido tenían los talleres, las conferencias, los grupos de reflexión, los grupos de estudio, las mesas redondas, la proyección de cine con debate, las exposiciones artísticas, propuestas que impactaron sobre la producción creativa feminista. A su vez existía una comisión de asistencia psicológica,

${ }^{3}$ Entre sus fundadoras se encontraban Marta Miguelez, Hilda Rais, Alicia D'Amico, María Luisa Lerer, María Luisa Bemberg, Sara Torres, Graciela Sikos, Lidia Marticorena, Ana Amado, entre otras.

4 “¡Casa Tomada! Un lugar para cada una y cada una en su lugar”, Tiempo Argentino, 13 de agosto de 1983, sección Mujer, .5 
sexológica y asesoramiento jurídico, para las mujeres que así lo requirieran. Todo ello se dio sin interrupción a lo largo de cinco años (1983-1988), tras lo cual el espacio se dedicó de lleno al asesoramiento y ayuda a mujeres con problemas de violencia de género, dejando de lado lo referido al campo artístico y cultural.

Al cumplir un año, las integrantes de Lugar de Mujer realizaron una fiesta de la que la prensa se hizo eco. Alicia D'Amico señalaba al respecto:

Para mí que Lugar cumpla un año es un éxito maravilloso.
Yo temía que por las circunstancias este episodio durara sólo
unos tres o cuatro meses. Teniendo en cuenta que nos
autofinanciamos, es un esfuerzo durar un año. Además, éste
no es sólo un lugar de encuentro nacional para la mujer, sino
también internacional. Cualquier mujer importante que llega
al país, visita Lugar y lo difunde en el mundo. Además aquí
le damos información sobre los movimientos feministas del
país, las últimas reivindicaciones, nuestros proyectos y así se
van con una idea general de la posición de la mujer
argentina.

Un elemento que destacaban las integrantes de este espacio era el placer que les daba el estar juntas, el encontrarse para disfrutar, ya sea en reuniones pactadas o inesperadas, lo cual es comprensible en aquél momento de recuperación de las libertades.

Las principales articulaciones que realizaron las feministas de Lugar de Mujer fueron con las Madres de Plaza de Mayo y con las agrupaciones de Derechos Humanos, situación que permitió unir luchas en el reciente contexto democrático. Sus reivindicaciones en la calle por la Ley de Patria Potestad Compartida (alcanzada en 1985 por la Ley 23264 y la Ley de Divorcio Vincular - conseguida en 1987 gracias a la Ley 23515 con la que se reformó el Código Civil), fueron fundamentales para lograr sus respectivas promulgaciones. A su vez pelearon por la participación de las mujeres dentro de los partidos políticos y dentro del parlamento, para lo cual fue de vital importancia crear conciencia dentro del colectivo femenino.

\footnotetext{
${ }^{5}$ Lugar de Mujer: vino y saladitos para el primer año de vida. In Tiempo Argentino, 25 de agosto de 1984, sección Mujer, 11
} 
El hecho de poder reflexionar críticamente sobre los modelos en los cuales habían sido educadas las mujeres, determinó que la experiencia personal se transformara en territorio político. Así se pasó de la anécdota a la categoría, y al hacerlo, se conceptualizó sobre ello. El concepto de experiencia, el cual ya había cobrado un valor político dentro de los grupos de concienciación de los feminismos de los 70 , pronto se manifestó como una herramienta metodológica que daba la posibilidad de construir otras interpretaciones de lo personal ${ }^{6}$. Teresa de Lauretis define esta noción: "Por experiencia no me refiero a lo que uno sabe o puede hacer bien, sino también al conjunto de hábitos, disposiciones, recuerdos, actitudes y expectativas que cada persona ha adquirido como resultado de la realidad social en la que ha vivido." En Lugar de Mujer se creó espacio de autoridad para la voz de las mujeres, esto posibilitó la reafirmación del yo y la potenciación de la autoestima de muchas mujeres, así indicaba una anónima:

Yo ya tengo 51 años, soy médica y siempre me desvaloricé mucho. A pesar de que en mi profesión me iba muy bien siempre me consideraba menos. Aquí fue casi increíble, empecé a darme cuenta que podía hablar, opinar, tener ideas que a otros le importan, encontré un grupo y un espacio. Eso ya es demasiado. ${ }^{8}$

En este contexto, Lugar de Mujer propició un juego de ida y vuelta entre el campo artístico local y el activismo feminista. Las artistas feministas llevaron problemáticas y debates a dicho espacio, a la vez que en sus obras cobró sentido la ideología feminista que allí circulaba, lo cual trajo por entonces un momento dorado para el arte feminista argentino.

1988.

${ }^{6}$ HARDING, S. Feminism and Methodology. Indianapolis, Indiana University Press,

${ }^{7}$ DE LAURETIS, Teresa. La creación artística y la autotraducción. In X. Arakistain y L. Méndez. (orgs.) Producción artística y teorías feministas del arte: nuevos debates IV. Vitoria, Centro Cultural Montehermoso, 2011, 138-149

${ }^{8}$ Lugar de Mujer: vino y saladitos para el primer año de vida. In Tiempo Argentino, 25 de agosto de 1984, sección Mujer, 11 


\section{El autorretrato: herramienta para el desafío de lo instituido}

Creo que no se ha dicho demasiado que la fotografía es un medio único e intransferible en la representación de una persona. Nadie puede posar por nosotras y la foto termina siendo un referente válido de nuestra percepción del adentro -nuestra imagen interna- y del afuera, nuestra apariencia. El confrontarnos con nuestra imagen produce una conmoción, una crisis que ayuda a la conceptualización del yo. La fotografía es así un vehículo de conocimiento; con ese sentido es utilizada en el taller. ${ }^{9}$

En Lugar de Mujer, Alicia D’Amico junto a la psicóloga Graciela Sikos organizaron el taller Autorretrato, con objeto de bucear en la identidad femenina. El mismo consistió en dos encuentros de cuatro horas de duración, uno en el estudio fotográfico que D'Amico compartía con la fotógrafa Sara Facio y el siguiente en la misma sede de Lugar de Mujer en el mes de mayo de 1984.

Las bases teóricas empleadas para esta propuesta de taller venían del campo de la psicología, específicamente del psicodrama y del teatro espontáneo. Su finalidad era alcanzar una autorreflexión sobre la identidad femenina que se pudiera reflejar en imágenes. Así recuerda Graciela Sikos:

La idea de hacer retratos de mujeres era de Alicia y yo agregué la metodología de taller, es decir: hacer un trabajo corporal, hacer una relajación, llevar elementos para trabajar. Todos los objetos que se usaron en las fotos los llevé yo. Las mujeres escogían qué elemento usarían para posar, había un espejo ante el que se veían, determinaban la forma en que posarían, etc. y Alicia respetaba esa decisión. Luego, en el momento que presentábamos las fotos tomadas por Alicia, yo hacía que cada mujer dijera cómo se veía y qué se le ocurría ante su propia imagen a través de un cuestionario. Estábamos todas juntas pero las fotos se las dábamos de a una. Yo tomaba nota sobre lo que cada mujer iba contestando. La idea de las preguntas y de la escucha sobre qué les pasaba frente a

${ }^{9}$ D’AMICO Alicia. Cómo Somos. en alfonsina, n 3, 12 de enero de 1984, 8. 
la propia imagen fue mía. Eso es un autorretrato para mí, cuando vos te ves, cuando tenés la foto entre las manos y te reconocés, decís esta soy yo. ${ }^{10}$

Mayra Leciñana, quien realizó uno de los talleres de Autorretrato, el dirigido a adolescentes, recuerda:

Al principio se planteaba un momento de distensión y de esparcimiento, caminábamos por ejemplo, con los ojos cerrados, se daba todo como para entrar en un clima de relajación. Después Graciela Sikos daba una charla planteando la idea de que uno puede construirse. Así es que nos proponía pensar cómo nos gustaría vernos, cómo nos percibimos. Ellas traían muchos elementos para que jugáramos a mostrarnos en un rol que se relacionara con cómo nos veíamos nosotras mismas: guantes, ropas, zapatos, mantos, encajes flores, corbatas. Una vez que protagonizábamos ese rol, Alicia nos tomaba una fotografía. Finalmente hacíamos un balance, una evaluación de cómo nos habíamos sentido con la imagen fotográfica que resultaba de este proceso de reflexión. ${ }^{11}$

Las participantes respondían preguntas que Sikos elaboraba para que expresaran lo que sentían ante la fotografía, esos textos acompañaban a las imágenes. El material de este taller formó parte de la muestra que se realizó en Lugar de Mujer al cumplirse un año de su fundación.

Al respecto la prensa se hizo eco. El periódico Tiempo Argentino publicó algunas fotografías de Autorretrato en un artículo escrito por Sara Facio, así decía:

El autorretrato es, por definición, la búsqueda de la propia imagen. Todas las disciplinas artísticas (pintura, literatura, etcétera) tienen ejemplos magistrales. Estamos frente al autorretrato de una no-artista, de alguien que sólo busca su identidad, de crearse aunque la mano técnica pertenezca a "otra". Pero, atención, "otra" que la mira sin prejuicios, sin preconceptos, que es sólo el espejo. Y corresponde a la idea

\footnotetext{
${ }^{10}$ Entrevista a Graciela Sikos, Buenos Aires, 22 de septiembre de 2016.

${ }^{11}$ Entrevista a Mayra Leciñana, Buenos Aires, 15 de enero de 2016.
} 
madre del autorretrato: autoconocimiento y aceptación no complaciente del yo. ${ }^{12}$

Una parte del material que resultó de este taller fue publicado en el periódico alfonsina, el cual había comenzado a circular en diciembre de 1983. Con el fin de vincular lo femenino al contexto nacional, esta publicación reflejó varias de las discusiones feministas así como su impacto en la realidad política. ${ }^{13}$ En el artículo que llevó por nombre Cómo Somos, Alicia D'Amico explicaba el sentido del taller de Autorretrato:

La hipótesis de trabajo sostiene que existe una mirada fotográfica femenina capaz de crear una nueva estética, redefiniendo el concepto tradicional de belleza; mirando de manera diferente, juzgando y creando de manera diferente. La mujer puede transformar la imagen de la mujer. (...) La identidad femenina pasa ahora a ser una cuestión de las mujeres. $^{14}$

Más allá de una lectura esencialista y/o de plantear argumentos que nos conducirían al binomio mujer/naturaleza temáticas en las que no creo que la fotógrafa estuviera interesada -, D'Amico se propuso investigar cómo la libertad sobre el propio deseo y el cuerpo femeninos podían crear otras imágenes de mujeres, diferentes a las que por entonces circulaban masivamente a través de los medios de comunicación. Los géneros del retrato y el desnudo fueron centrales para ello.

En efecto, la fotógrafa analizó el impacto de la heteronormatividad sobre las construcciones de lo femenino. Aquellas mujeres concienciadas, que cuestionaron el sistema ideológico heterosexual, buscaron crear imágenes que fueran más allá de las

${ }^{12}$ FACIO, Sara. La mirada femenina puede volverse un bumerán. Olvidándose de la versión que esperan los demás, varias mujeres ensayan sus primeros autorretratos fotográficos y aprenden a reconocer su verdadera imagen o a cambiarla. In Tiempo Argentino, 13 de agosto de 1983, sección Mujer, 2.

13 Para más información sobre el periódico alfonsina ver: BERTÚA, Paula; DE LEONE, Lucía. Identidades textuales y autorales en alfonsina: un juego de representaciones. In XXIII Jornadas de Investigación del Instituto de Literatura Hispanoamericana, Buenos Aires, 2009.

${ }^{14}$ D’AMICO Alicia. Cómo Somos. en alfonsina, n 3, 12 de enero de 1984, 8. 
reguladas por el patriarcado. La fotografía, para D'Amico, se constituyó en el medio que permitía el autoconocimiento. Así señalaba en un texto del año 1984:

Las mujeres recibimos las pautas de nuestra identidad social a través de leyes, instituciones y costumbres. Se materializa a través de la imagen y la palabra. La reprobación social, el "que dirán", en cuanto nos apartamos de las condiciones establecidas, actúan como censores y contenedores de cualquier gesto independiente. Las mujeres estamos condicionadas por las imágenes que nos muestran de otras mujeres, inducidas desde el exterior por la sociedad." 15

Dada la recuperación de libertades que por entonces vivía la Argentina, se hacía urgente que las mujeres pensaran en cómo querían verse y ser vistas, cómo querían nombrarse y ser nombradas. Había fuertes esperanzas de cambio y para ello debían pensarse ellas mismas antes que ser pensadas por otros. Ellas buscaban ser las protagonistas de sus propias vidas.

Una de las integrantes del taller, Cecilia, decía frente a la imagen escogida por ella misma:

Es lo que yo pensé mostrar y que me pasa a mí y a varias mujeres igual: una parte aprendida, moldeada por la educación, por los medios de vida, tiene que ver con la mujer objeto. La otra parte mía, que fui eligiendo a través de mi vida, que no tiene que ver con los modelos, que está expuesta sin disfraces, sin pintura, que piensa, que reflexiona.

¡En mí conviven esas dos! Eso es permanente. A veces tironea más una que la otra, pero bueno... es así! CECILIA. ${ }^{16}$

El ejercicio de pensarse a sí mismas a través de la fotografía, nos lleva a destacar ciertas particularidades del contexto argentino durante los años 80 . Como señalamos, junto a la salida de un régimen

15 D'AMICO Alicia. "Salud, identidad y socialización. Relaciones con la imagen fotográfica” en ¡Es preciso volar! Primer Encuentro Regional sobre la Salud de la Mujer. Bogotá, Ministerio de Salud, 1984, 52.

${ }^{16}$ D'AMICO, A. Cómo Somos. In alfonsina, n 3, 12 de enero de 1984, 9 
dictatorial genocida, con secuelas graves para los derechos humanos y los vínculos sociales, coincidieron la madurez alcanzada por los feminismos locales, la llegada de mujeres exiliadas que venían con información fresca sobre los feminismos extranjeros y la necesidad genuina de socialización, de recuperación de la comunicación física y afectiva entre las mujeres. Los comentarios de las integrantes de Autorretrato reflejaron estas características del entorno. Es el caso de Ana:

Me gustan más las fotos en las que todas salimos de nuestras habituales imágenes y mostramos esos costados en donde las defensas están más bajas. Sentí que el grupo me aportaba cosas que me faltaban. Me sorprendió mi foto porque muestra un matiz de mi personalidad siempre oculto: la melancolía. La mirada angustiada refleja mucho de la forma en que me buscaba; entre angustiada y perdida. Con la boina estoy más desafiante, y es la que más me identifica, porque a veces sobrepongo el desafío a cualquier estado de ánimo. ANA ${ }^{17}$

Ana era la profesora e intelectual Ana Amado (Santiago del Estero 1946 - Buenos Aires 2016) ${ }^{18}$ quien había regresado recientemente al país, tras el exilio junto a su marido, Nicolás Casullo, primero en Caracas (1974-1975) y luego en México (19761983). Ella perteneció a esas mujeres curiosas e informadas que ansiaban insertarse en el clima de apertura cultural, vivido por entonces en la ciudad de Buenos Aires. La imagen reflejaba la melancolía en la mirada, tal como apuntaba la retratada, quizás por la experiencia nómade del exilio. La angustia sentida por cómo reconstruir su vida en una Argentina que buscaba revivir sin olvidar el pasado, fue algo característico de muchas/os exiliadas/os de aquellos años. En este contexto, algunas mujeres consideraron que era imprescindible pensar en cómo querían verse y ser vistas, cómo querían nombrarse y ser nombradas. Había esperanzas de cambio y ellas se sentían protagonistas de la historia. El corte fortuito realizado por la cámara al enrollar la película, fue preservado por la fotógrafa

\footnotetext{
${ }^{17}$ D’AMICO, A. Cómo Somos. In alfonsina, ${ }^{\circ}$ 3, 12 de enero de 1984, 9

${ }^{18}$ Ana Amado fue corresponsal en Argentina de Fempress, Red Alternativa de Prensa Feminista para América Latina desde 1983 a 2001.
} 
como parte de la obra, y sin lugar a dudas, generó un marco misterioso para el rostro de Ana.

Considero - siguiendo a Teresa de Lauretis - que la construcción de la subjetividad se da a partir de la intersección e interacción de distintos ejes de diferenciación tales como clase, raza, etnia, sexualidad, franja etaria, etc. Los mismos tienen una modalidad de acción en los que se ha detenido a pensar la citada teórica, quien sostiene:

Estos ejes son así considerados paralelos o de valor similar aunque con "prioridad" diversa según cada mujer. Para algunas, el eje racial puede tener prioridad sobre el eje sexual a la hora de definir la identidad y la base material de la subjetividad; para otras mujeres puede tener prioridad el eje sexual; para otras puede ser el eje étnico-cultural el que tenga prioridad en un momento dado. ${ }^{19}$

En los talleres participaban mujeres de distintos países, que como ya había señalado Alicia D'Amico en una cita más arriba, llegaban a Lugar de Mujer en sus visitas a la Argentina. Es así que Frescia, una mujer de origen peruano, participó del taller Identidad, e indicó lo siguiente ante la fotografía seleccionada:

Quería representarme en el momento en que comencé a mirarme sin esconderme. Sin hacerme trampas, por eso el desnudo. Me llama mucho la atención la cicatriz en el estómago, nunca la vi así. Quizás narra un segundo nacimiento. La cicatriz me hace tener presente una agresión innecesaria. Veo mi cuerpo sólido, fuerte, hermoso. Pero mi imagen interna no la veo igual, tengo muchos miedos, nudos aún sin desatar. Hay mucho por andar. Tengo paciencia y esperanza. $^{20}$

En ese sentido no es un dato menor que los talleres planteados por Sikos y D'Amico - ya sea juntas o de manera

${ }^{19}$ DE LAURETIS, Diferencias. Etapas de un camino a través del feminismo. Madrid. Horas y horas, 2000, 111-152

${ }^{20}$ Narración que acompaña a la imagen Taller Identidad, 1984. Archivo Alicia D'Amico, fotografía inédita del archivo. 
independiente - tuvieran un alto nivel de convocatoria. Había una necesidad de pensar en la subjetividad, de revisarla y reinscribirla, de dar voz a aquellos deseos latentes y poder protagonizar la vida dejando de lado la esclavitud de los mandatos.

Ilse Fusková y la mirada de una fotógrafa hacia la modelo

En el mercado siempre me deleita el zapallo abierto. Dentro de sus dorados y sutiles telones son escenarios para una liberadora fantasía.

Y junto con la poderosa alineación de sus semillas, se tradujo para mí en la imagen de la fertilidad de la mujer.

Fértil con su vientre.

Fértil con su mente.

Sus hijos y sus hijas y sus ideas pueden cambiar el mundo.

Ilse Fusková, El zapallo, 1982

Ilse Fusková (Buenos Aires, 1929) es conocida en Argentina por ser una importante activista lesbiana, fundamental en la lucha por la despatologización de la homosexualidad y por el derecho del colectivo lésbico a tener una voz y una historia propias. Sin embargo, desde muy joven fue una figura intelectualmente inquieta, hecho que la llevó a desarrollar varias actividades en su vida. De padre alemán y madre checoslovaca, Felka - pseudónimo con el que firmó sus fotografías de los años 50 - estudió periodismo y se desempeñó también como azafata. Colaboró con reportajes y comentarios de cine en revistas como El Hogar, Mundo Argentino, Para Ti y Lyra. Tras desarrollar algunas series fotográficas durante los años 50, Fusková abandona por casi dos décadas este arte, retomándolo a principios de $\operatorname{los} 80$.

En mayo de 1978, Fusková se unió al MLF, momento en que la agrupación sobrevivía sólo a través de la revista Persona ${ }^{21}$. En este contexto feminista, la fotógrafa comenzó a desarrollar una investigación sobre el desnudo femenino. El estudio de la mirada

${ }^{21}$ BELLUCCI, Mabel. Arráncame la vida. In Las 12, 14 de septiembre de 2012. https:/www.pagina12.com.ar/diario/suplementos/las12/13-7503-2012-09-15.html 
femenina en relación con la construcción de la identidad la condujo a la creación de la serie El zapallo, la cual presentó en los Talleres Brígida Rubio en 1982 y en Lugar de Mujer luego de la fundación de dicho espacio, en noviembre de 1983. Dicha serie está formada por diez fotografías las que refieren directamente a la fecundidad femenina, tanto física como mental. La invitación a la exposición estaba acompañada de un pequeño poema de la misma Fusková, que reprodujimos más arriba. ${ }^{22}$

La serie se detenía poéticamente en dos desnudeces: la del zapallo, en toda su carnosidad interna, y la de la modelo ${ }^{23}$. El cuerpo del vegetal y el de la mujer se entrelazaban en exuberante concavidad y redondez. La modelo transmitía una fuerte personalidad, “(...) ella instintivamente se movía y yo le tomaba fotos", señala la fotógrafa. ${ }^{24}$ Sin duda el zapallo le reflejaba toda una geografía especial:

(...) entrar en la verdulería y ver esos zapallos grandes cortados por la mitad, ahí veía un mundo de magia porque está lleno de telones dorados, de semillas, para mí eso era la magia. (...) Para mí era una cosa divina, llena de fertilidad y me dije, yo quiero hacer una serie de fotografías con esto. Me compré, entonces, el zapallo. ${ }^{25}$

La verdura abierta, con todo su cuerpo interno en exhibición se presentaba como símbolo de vida. Fusková se detuvo en analizar las relaciones existentes entre el cuerpo del vegetal y el femenino. En una de las fotografías, el zapallo aparecía sostenido por la modelo

\footnotetext{
${ }^{22}$ Para ver algunas de las fotografías de la serie El zapallo consultar: María Laura Rosa: "Repensando identidades e imágenes corporales. La fotografía de Ilse Fusková tras el retorno de la democracia en Argentina" en Re-d. Arte, cultura visual y género, Programa Universitario de Estudios de Género, Instituto de Investigaciones Estéticas, Universidad Autónoma de México, ํ2, 2012. http://www.pueg.unam.mx/revista2/?p=1290 [última consulta: enero 2014]

${ }^{23} \mathrm{La}$ modelo posaba frecuentemente para el pintor Raúl Soldi, era conocida de Silvia Schmid, amiga de Fusková y quien se la presenta para este trabajo.

${ }^{24}$ Entrevista a Ilse Fusková, 7/VIII/2008.

${ }^{25}$ Entrevista de María Laura Rosa a Ilse Fusková y conferencia de Ilse Fusková en el Seminario de Doctorado Arte y política en/desde los conceptualismos: cruces, desbordes, impugnaciones. Impartido por Ana Longoni, Assumpta Bassas Vila y Fernando Davis en la Facultad de Ciencias Sociales, Universidad de Buenos Aires, 29 de agosto de 2008. Ver: María Laura Rosa: Fuera de discurso. El arte feminista de la segunda ola en Buenos Aires, Madrid, UNED, 2012, http://e-spacio.uned.es:8080/fedora/get/tesisuned:GeoHis-Mlrosa/Documento.pdf [última consulta: enero de 2014]
} 
sobre su vientre, arriba de su pubis. El sexo de la mujer se situaba en la misma línea que la apertura del corazón de la verdura, el cual despliega a ambos lados un universo de semillas y tejidos. La fotógrafa comentó que:

(...) no veía la relación con la vagina. Había gente que se reía porque yo mostré eso en San Telmo en el ochenta y dos. Pero eso de que fuera una vagina, un útero me sucedió más tarde. (...) Yo amo esos trabajos porque siento que tienen varios niveles de lectura. (...) ¡Cómo a medida que pasan las cosas una puede ver desde otro lugar el trabajo propio! ${ }^{26}$

Al ubicar la verdura entre los pechos y el pubis, esta vez tapando el sexo, el juego de relaciones cambia por el sólo desplazamiento de las manos de la figura sobre el cuerpo del zapallo. En una de las fotos, la modelo cubrió parte del corazón del vegetal con una de sus manos mientras con la otra toca la cáscara como acariciándola. $\mathrm{Su}$ rostro aparecía casi recortado por el encuadre, Fusková se centró en el torso de la mujer, destacaba así uno de los pechos que descansaba sobre la verdura. En otra de las fotos, la posición de la modelo transmitía gran libertad. Las luces se derramaban de forma uniforme, bañando el cuerpo de la mujer y del vegetal por igual. La iluminación destacaba la sedosidad y el color de la piel de ambas. Mujer y zapallo son una misma figura, convivían en ellas colores y texturas que se unían entre sí.

Fusková expresó que el cuerpo desnudo de la mujer es un tema tabú en nuestra sociedad:

La mayoría de las mujeres en la cultura occidental nos vemos a través de la mirada distorsionada de una sociedad dominada por varones. Esto es verdad para todo nuestro ser y muy especialmente para la percepción que tenemos de nuestro propio cuerpo. (...) Yo pienso que el cuerpo de la mujer es objeto de deseo del macho, que ese cuerpo le fascina y también le da miedo. Sin embargo el cuerpo desnudo de la mujer, sin las contorsiones de la seducción, es una imagen

\footnotetext{
${ }^{26}$ Entrevista a Ilse Fusková, 7/VIII/2008.
} 
prohibida. (...) La desnudez del cuerpo de la mujer es un derecho que nos es absolutamente negado. ${ }^{27}$

En 1986, una de las fotos fue seleccionada para formar parte de la exposición internacional Mujeres fotografian mujeres, organizada por la Volkshochschule de Munich ${ }^{28}$. Era la única obra en blanco y negro de la serie. La modelo estaba sentada sobre el piso, llevaba la verdura abierta sobre su pubis. En verdad, el zapallo parecía ocupar el lugar de su pubis. Sus manos se unían en suave gesto sobre la cáscara. Los pechos quedaban tenuemente ocultos entre la verdura y los brazos. Piernas y brazos enmarcaban al zapallo. El rostro de la modelo poseía una mirada concentrada en el propio placer de estar allí. Una vez más, el contraste entre el interior y el exterior de las figuras convivían conformando un único y particular cuerpo.

La preocupación por crear una iconografía que reflejara la mirada de la mujer hacia su propia desnudez física, conformando una otra poética del cuerpo femenino, guió a Fusková hacia obras en donde la naturaleza y la anatomía femenina se complementaban. El zapallo, a través del recurso de la luz, se incorporaba al cuerpo de la mujer como una redondez más, como un órgano más, como la misma piel.

La serie buceó en la dimensión corporal de la experiencia femenina, la cual ha sido negada durante siglos en el terreno de la representación visual. El arte feminista, como práctica cultural, generó nuevas perspectivas y significados en el campo de las visualidades. Griselda Pollock recuerda que las imágenes y textos no son espejos que se limitan a reflejar el mundo. La representación es algo reformulado y codificado en términos retóricos, textuales o pictóricos, distintos a su existencia social: “(...) podemos entender la representación como la articulación en una forma visible $o$ socialmente palpable de procesos sociales que determinan la

27 FUSKOVÁ, Ilse; MAREK, Claudina. Amor de mujeres. El lesbianismo en la Argentina hoy. Buenos Aires, Planeta, 1994, 42-43.

${ }^{28}$ Según Fusková, la muestra internacional estuvo integrada por 161 mujeres de 27 países, y se llevó a cabo desde el 3 de septiembre al 20 de octubre de 1986 en Múnich, luego itineró por varios países. 
representación pero que, a su vez, se ven afectados y alterados por las formas, prácticas y efectos de ella misma"29.

En esta dirección, Lynda Nead apunta:

No puede haber un cuerpo sin ropa que sea 'otro' del desnudo, porque el cuerpo siempre está en representación. Y, puesto que no cabe el recurso a un cuerpo semióticamente inocente $y$ sin mediaciones, debemos contentarnos con investigar las diferentes maneras en que los cuerpos de las mujeres son representados y con promover nuevas imágenes corporales e identidades nuevas. ${ }^{30}$

Asimismo, Julia Antivilo Peña alude a la cuestión del cuerpo como una temática central para el feminismo:

Si bien dentro de las artistas feministas no existió un manifiesto o declaración de principios, lo que sí existió fue más bien una motivación común que fue la temática del cuerpo, a la que tomaron como una práctica de estrategia y punto de encuentro. La práctica artística y la producción de nuevos significados principalmente para el cuerpo de las mujeres fue la inscripción de su compromiso político. El cuerpo, fue el sitial desde donde politizar sus obras pues éste había funcionado -y sigue- como un dispositivo de símbolos y objeto de las representaciones e imaginarios que se han construido social y culturalmente sobre las mujeres. ${ }^{31}$

Tanto el binomio mujer-naturaleza como su relación con la fertilidad femenina jugaron un papel central en las obras de Fusková. Pese a ello, el concepto de la artista no buscó situarse en la eterna visión patriarcal de la relación mujer-naturaleza ya que para la fotógrafa la fertilidad era también cualidad del pensamiento

${ }^{29}$ POLLOCK, Griselda. Visión and difference. Feminity, Feminism and the Histories of Art. London and New York, Routledge, 1988, 7.

${ }^{30}$ NEAD, Lynda. El desnudo femenino. Arte, obscenidad y sexualidad. Madrid, Tecnos, 1998,34 .

31 ANTIVILO PEÑA, Julia. Entre lo sagrado y lo profano se tejen rebeldias. Arte feminista latinoamericano. México 1970-1980. Santiago de Chile, 2006, 32. http://museodelasmujeres.co.cr/wp-content/uploads/2013/06/Antivilo-Julia-Entre-Lo-Sagrado-YLo-Profano-Se-Tejen-Rebeldi\%CC\%81as-2006.pdf [última consulta: enero 2014] 
femenino. Con todo, la serie El zapallo puede ser analizada a la luz de cierta iconografía femenina reivindicada por el movimiento de mujeres de los años $70^{32}$. En relación a esto, en 1975 la crítica estadounidense Lucy Lippard aconsejaba:

Al mismo tiempo la igualdad [en relación a un arte que reflejara la diferencia sexual] no es necesariamente recostarse sobre la soledad de la androginia. Si nosotras como mujeres no retornamos a las fuentes de nuestro arte y nuestra experiencia antes que intentemos trascender lo genérico, los resultados serán por lejos menos fértiles. ${ }^{33}$

La cuestión de la mitología femenina - uno de los temas del feminismo anglosajón más característicos de la década del 70 - ha sido vista con reticencia por muchas feministas, en los últimos años, debido a cierta posición esencialista que originan los binomios mujermaternidad, fecundidad-Madre Tierra. Sin embargo no podemos ignorar que Fusková se nutrió de los estudios sobre el matriarcado y el culto a la Diosa que afloraron durante la segunda ola del movimiento. Ella buscará reflexionar sobre la experiencia física y espiritual desde un cuerpo de mujer, es por ello que resulta importante tener en cuenta el recurso a la mitología femenina que empleó la artista, y de esa manera indagar en su serie fotográfica ${ }^{34}$.

${ }^{32}$ Empleo el término iconografía femenina tal como lo enunciara Lucy Lippard en su ensayo "Prefaces to Catalogs of Three Women Exhibitions" de 1973. Allí la teórica y crítica estadounidense señala: “(...) es innegable que la experiencia -social y biológica- de una mujer en esta sociedad es simplemente diferente de la de un hombre. Si el arte emerge del interior, como debería ser, entonces el arte de los hombres y de las mujeres tienen también que ser diferentes. Y si ese factor no se exhibe en los trabajos de las mujeres, nos es otro el motivo más que su represión. Para cada época pueden especificarse esas diferencias, hay infinitos momentos en las cuales quedan éstas fuera del alcance de los análisis. Quizás sea imposible precisarlas hasta que el lugar que ocupe la mujer en la sociedad no sea verdaderamente en igualdad de condiciones y que los trabajos de las mujeres puedan ser estudiados fuera de los confines de la opresión que los condicionan". En LIPPARD, Lucy. The Pink Glass Swan. Selected Feminist Essays on Art. New York, The New Press, 1995, 57.

${ }^{33}$ LIPPARD, Lucy. The Pink Glass Swan. Selected Feminist Essays on Art. New York, The New Press, 1995, 59.

${ }^{34}$ Guía también mis interpretaciones el saber que uno de los libros de cabecera de Ilse Fusková era por entonces GADON, Elinor W. The Once \& Future Goddess. A Symbol for Our Time. San Francisco, Harper and Row, 1989. Dicha publicación fue adquirida por la artista el mismo año de su edición porque "(...) la temática, de la que ya me había enterado antes a través de las revistas feministas anglosajonas, me apasionaba”. Entrevista a Ilse Fusková, 7/VIII/2008. 
Fusková estuvo subscripta a la revista Woman of Power durante los años 80. Esta última se presentaba como un magazine de feminismo, espiritualidad y políticas. Allí tomó contacto con los estudios de Marija Gimbutas y Merlin Stone sobre el culto a las diosas en las culturas neolíticas de occidente. Señala Ethel Morgan que

(...) la Diosa era para las culturas pre patriarcales una figura cósmica total, creadora del universo y de sus leyes, gobernante de la naturaleza, el destino, el tiempo, la eternidad, la verdad, la sabiduría, la justicia, el amor, el nacimiento y la muerte. Sólo una sostenida campaña de denigración y demonización de lo divino pudo hacer que los occidentales la olvidaran. ${ }^{35}$

El desarrollo de la arqueología desde una mirada feminista disparó, durante los 70, nuevas interpretaciones sobre los cultos practicados por algunos pueblos neolíticos de occidente. Señala Gloria Feman Orenstein:

Aunque nuestra propia historia ${ }^{36}$ occidental sobre destacadas madres, desde Hildegard von Bingen a Elizabeth Cady Stanton crearon comentarios feministas, críticas e imágenes en respuesta a lo divino o sagrado formulado desde el interior de la historia patriarcal, los '70 constituyeron el primer momento en que las creaciones artísticas de las mujeres se extendieron, de forma autoconsciente, más allá de los parámetros y referencias de la historia del arte patriarcal, así como también reclamaron modelos visuales matriciales $^{37}$ y materiales del pasado, tan remotos como el Alto Paleolítico y el Neolítico. Aquellas imágenes contienen una vital propia historia de las relaciones de mujeres con lo sagrado así como de las dimensiones seculares de sus palabras. Fueron, sin

\footnotetext{
${ }^{35}$ MORGAN, Ethel. Diosa. In GAMBA, Susana B. (org.). Diccionario de estudios de género y feminismos. Buenos Aires, Biblos, 2007, 92.

${ }^{36} \mathrm{He}$ traducido herstory como 'propia historia', la autora lo emplea para contrastar con history, vinculado a las narrativas patriarcales gracias al juego de palabras que se puede hacer en la lengua inglesa. [cursiva empleada por mí para destacar la traducción]

${ }^{37}$ He traducido matristic como 'matricial', refiere para la autora 'Diosas Madres'.
} 
embargo, las interpretaciones artísticas de Merlin Stone y Marija Gimbutas que eventualmente reinterpretaron el significado de aquellas antiguas piezas artísticas, integrándolas a nuestros criterios históricos y arqueológicos, haciéndolas accesibles y significativas para las artistas feministas de los $' 70 .^{38}$

En los Estados Unidos, los vínculos entre el culto a la Diosa y el arte se vieron enriquecidos por la recepción y difusión de las nociones de arquetipo e inconsciente colectivo de Carl Gustav Jung, las que ya venían influyendo sobre la creación desde décadas atrás. Los preceptos del psicoanalista suizo posibilitaron interpretaciones sobre los modelos constantes en el inconsciente colectivo a la vez que motivaron explicaciones ante la cuestión de por qué muchas artistas contemporáneas, quienes nunca habían leído sobre la Diosa, coincidían en trabajar con imágenes que contenían símbolos antiguos de sociedades pre patriarcales.

Fusková señaló que el culto a la Diosa fue ignorado en la historia por varias razones:

(...) debemos decir que las extraordinarias manifestaciones artísticas de la cultura del neolítico eran conocidas, sólo que no eran atribuidas a una cultura matrilineal, a lo que llamamos la cultura de la Diosa. Lo que se tenía por verdad no estaba basado en estudios serios, sino en meras 'interpretaciones' que partían del consabido prejuicio patriarcal, (...) debemos saber que uno de los secretos históricos mejor guardados es que prácticamente todas las tecnologías materiales y sociales básicas para la civilización se desarrollaron antes de que se impusiera una sociedad dominadora. Es decir, antes del patriarcado. ${ }^{39}$

${ }^{38}$ FEMAN ORENSTEIN, Gloria. Recovering Her Story. Feminist Artists Reclaim the Great Goddess. In BROUDE, Norma; GARRAND, Mary (org.). The Power of Feminist Art. The American Movement of the 1970s, History and Impact. New York, Harry N. Abrams, Inc., Publishers, 1994, 174. [El entrecomillado y los asteriscos son míos] Orenstein emplea términos creados por las feministas anglosajonas que no tienen traducción al español. He traducido matristic como 'matricial', el mismo significa para la autora 'Diosas Madres'.

39 FUSKOVÁ, Ilse; MAREK, Claudina. Amor de mujeres. El lesbianismo en la Argentina hoy. Buenos Aires, Planeta, 1994, 149-150. 
En el culto a la Diosa confluyeron varios cuestionamientos, debates y perspectivas de análisis que se desarrollaron durante la segunda mitad de los 70 y los primeros 80. Gloria Feman Orenstein explica que la Diosa afianzó transformaciones en varios niveles vinculados con el campo artístico:

(...) cambios en el género del Creador, acompañados por la veneración a la madre tierra, al pacifismo asentado en las más antiguas religiones (...) restableciendo la propia historia ${ }^{40}$ borrada desde el lejano Alto Paleolítico (25.000 a. C.), buscar la integración de espíritu y materia, cielo y tierra, masculino $\mathrm{y}$ femenino, humano y formas de vida no humanas, el empoderamiento de la mujer al reconectarse con las antiguas energías de las mujeres mitológicas y de las reales que vivieron en sociedades matriarcales $(\ldots) .{ }^{41}$

De esta manera, la recuperación de lenguajes artísticos denostados por el relato canónico de la disciplina de la historia del arte y de su sistema expositivo, tales como la cerámica y las artes de la aguja, cobraron fuerza al calor del rescate de culturas antiguas.

La serie El zapallo permitió a Ilse Fusková profundizar en su propia vivencia femenina en el que el cuerpo funcionaba como un elemento político. Toda su experiencia personal fue vía de formulación estética a la vez que política y será fundamental para el desarrollo activista en el que se embarcará unos años más tarde, cuando se asuma lesbiana.

\section{Conclusiones}

La recuperación democrática argentina trajo una imperiosa necesidad por la reconstrucción de los vínculos sociales que la última dictadura militar había destrozado. Así las mujeres volvieron a

${ }^{40}$ Léase Herstory.

${ }^{41}$ FEMAN ORENSTEIN, Gloria. Recovering Her Story. Feminist Artists Reclaim the Great Goddess. In BROUDE, Norma; GARRAND, Mary (org.). The Power of Feminist Art. The American Movement of the 1970s, History and Impact. New York, Harry N. Abrams, Inc., Publishers, 1994, 187. 
reunirse y retomaron la agenda feminista que había quedado paralizada tras el golpe militar de 1976.

Con el entusiasmo de los aires democráticos que comenzaron a correr prácticamente durante los últimos meses del gobierno de facto, un grupo de mujeres llevaron a cabo el sueño de tener un espacio de reuniones, encuentros y reflexión de y para las mujeres: así nació Lugar de Mujer, sitio que refleja mejor que cualquier otro, las esperanzas y los anhelos de cambio del colectivo femenino.

Conformado desde sus inicios como un espacio plural, en sus talleres se trabajaron diversas temáticas. Una de ellas fue la cuestión de la identidad a través de la fotografía, la cual estaba vinculada a la necesidad de auto reconocimiento de las mujeres, más allá de los mandatos de belleza y de la esclavitud al deseo masculino que se manifestaba a través de los medios de comunicación de la época. Los condicionamientos sociales y las demandas domésticas, condicionaban deseos, conductas y una imagen personal. Es así como Alicia D’Amico buscó a que cada mujer pudiera bucear en su identidad, para luego reflejarla a través de la fotografía. En este camino fue fundamental la psicóloga Graciela Sikos, quien diseñó toda una serie de ejercicios que preparaban a las mujeres para la reflexión y el rescate de su yo.

Dichas búsquedas estuvieron en sintonía con las planteadas por la fotógrafa Ilse Fusková, quien a través de sus serie El zapallo, prácticamente de la misma época que la conformación de Lugar de Mujer, en donde la exhibirá, se propone reflexionar sobre la desnudez del cuerpo femenino ¿Cómo una fotógrafa puede capturar la belleza del cuerpo de la mujer, trascendiendo las construcciones históricas que han condicionado su representación fotográfica? ¿Una mujer observa desde otros parámetros el cuerpo de otra mujer? ¿Dónde se detiene? ¿Qué observa? ¿Sus reflexiones visuales sobre el cuerpo femenino constituyen una mirada femenina?

Todos estos análisis conviven al mismo tiempo en la Buenos Aires de la primera mitad de los años 80, en donde comienza a conformarse un recorrido artístico feminista que retomó lo realizado durante los años 70 y dejó un verdadero legado para el siglo XXI. 


\section{Bibliografía}

ANTIVILO PEÑA, Julia. Entre lo sagrado y lo profano se tejen rebeldías. Arte feminista latinoamericano. México 1970-1980. Santiago de Chile, 2006.

DE LAURETIS, Teresa. La creación artística y la autotraducción. In X. Arakistain y L. Méndez. (orgs.) Producción artística y teorías feministas del arte: nuevos debates IV. Vitoria, Centro Cultural Montehermoso, 2011.

FEMAN ORENSTEIN, Gloria. Recovering Her Story. Feminist Artists Reclaim the Great Goddess. In BROUDE, Norma; GARRAND, Mary (org.). The Power of Feminist Art. The American Movement of the 1970s, History and Impact. New York, Harry N. Abrams, Inc., Publishers, 1994.

FUSKOVÁ, Ilse; MAREK, Claudina. Amor de mujeres. El lesbianismo en la Argentina hoy. Buenos Aires, Planeta, 1994.

GADON, Elinor W. The Once \& Future Goddess. A Symbol for Our Time. San Francisco, Harper and Row, 1989.

GAMBA, LIPPARD, Lucy. The Pink Glass Swan. Selected Feminist Essays on Art. New York, The New Press, 1995.

Susana B. (org.). Diccionario de estudios de género y feminismos. Buenos Aires, Biblos, 2007.

HARDING, S. Feminism and Methodology. Indianapolis, Indiana University Press, 1988.

NEAD, Lynda. El desnudo femenino. Arte, obscenidad y sexualidad. Madrid, Tecnos, 1998.

POLLOCK, Griselda. Visión and difference. Feminity, Feminism and the Histories of Art. London and New York, Routledge, 1988.

RECEBIDO EM: 24/09/2018

APROVADO EM: 21/10/2018 
